\title{
Mothers' Knowledge, Attitude and Practice about Infant Feeding and Weaning Food in Sylhet: An Empirical Study
}

\author{
Md. Abdul Hadi Suhag ${ }^{1 *}$, Mahbuba Akter ${ }^{2}$ \\ ${ }^{1}$ Lecturer, CRP Nursing College Savar, Dhaka, Bangladesh \\ ${ }^{2}$ Nursing Instructor, Enam Nursing College, Savar, Dhaka, Bangladesh
}

DOI: $10.36348 /$ sjnhc.2020.v03i11.009

| Received: 09.11.2020 | Accepted: 22.11.2020 | Published: 25.11.2020

*Corresponding author: Md. Abdul Hadi Suhag

\section{Abstract}

A cross-sectional descriptive study was carried out to assess the knowledge, attitude and practice about infant feeding and weaning food among the mothers of under 2 years children. The study was conducted at M. A. G. Osmani Medical College Hospital, Sylhet period December 2015 to February 2016 by interviewing a total 100 respondents in paediatric ward by using semi-structured questionnaire. Modes of thermoregulation identified included knowledge $81 \%$ respondents were known duration of exclusive breast feeding 6 months. 75\% respondents did not know about benefits of breast milk. $45 \%$ respondents known about breast feeding had contraceptive benefits, 55\% respondents were did not known about breast feeding had contraceptive benefits. Modes of face washed before feeding included $80 \%$ respondents did not know and $20 \%$ respondents were known about washed the hands before feeding. $91 \%$ respondents were known started time of weaning food after 6 months. Breast milk protect child from illness $85 \%$ respondents were did not know and only $15 \%$ respondents were known. Modes of weaning food included $68 \%$ respondents given hotchpotches as a first weaning food and only $16 \%$ mothers were given cerelac as first food. $50 \%$ respondents given complementary feeding 2-3 meals/ day and $28 \%$ were given 4-5 meals/day. $78 \%$ respondents said that bottles feed safer for baby. Modes of colostrum identified included $80 \%$ respondents known about to feed the baby, $17 \%$ respondents threw it. $45 \%$ respondents were known about breast feed the baby as soon as possible soon after delivery, $27 \%$ respondents were known within half an hour.75\% respondents said that other food given besides breast milk before 6 months. Finding of the study showed that $69 \%$ infant mothers had average knowledge, $23 \%$ had good knowledge \& $8 \%$ had poor knowledge. Among infant mothers nearly $54 \%$ had positive attitude and $46 \%$ had very positive attitude about infant feeding and weaning.

Keywords: Mothers, Knowledge, Infant Feeding, and Weaning Food.

Copyright (C) 2020 The Author(s): This is an open-access article distributed under the terms of the Creative Commons Attribution 4.0 International License (CC BY-NC 4.0) which permits unrestricted use, distribution, and reproduction in any medium for non-commercial use provided the original author and source are credited.

\section{BACKGROUND OF THE STUDY}

Mother is the most important person in a baby's life for both its physical as well as its psychosocial care and growth [1]. The mother-infant relationship is the child. From the very first moments of life a baby begins interacting with its mother [1]. Mother's health, her education, her beliefs and attitude regarding child-rearing are important milestones on the road of child's health right from in utero period [1].

Infants are particularly vulnerable. During the transition period when complimentary feeding beings. Ensuring that the nutritional needs of the infants are met thus requires that complimentary foods are; timely, adequate, and safe, properly fed [2]. Breast feeding is a biological and cultural system especially geared to preserve maintain and perpetuate the human race. Mother should start breast feeding very early within one to two hours of birth. Breast milk provides the main source of nourishment in the $1^{\text {st }}$ year of life. In some society's lactation continues to make and important contribution to the child nutrition for 18 month or longer [3]. It is common knowledge that breast feeding is important for optimal infant feeding [2]. The first milk which is called colostrum in the most suitable food for the baby during early period, because it contains a high concentration of protein and other nutrients the body needs. It is rich in anti-infective factors which protect them against respiratory infections and diarrheal disease, supplementary feeds are not necessary. The regular milk comes on the $3^{\text {rd }}$ to $6^{\text {th }}$ days after birth [4]. The World Health Organization (WHO)and United Nation International Children's Emergency Fund (UNICEF) unanimously recommend breast-feeding babies aged 0-6 months exclusively with breast milk, starting weaning only after the six month and breast- 
feeding until the baby in 2 years old. According to World Hunger Facts 2008-2012; exclusive breast feeding <6 months $64.1 \%$, early initiation of breast feeding $47.1 \%$, at age 2 breast feeding $89.6 \%$.

Breast milk alone can be used for feeding babies in the first six months of life, but from then on complimentary feeding is necessary [2]. According to WHO [5] appropriate weaning should be timely, adequate, and safe and properly fed [4]. Weaning means addition or introduction of semi-solid foods alone with continuation of breast feeding as soon as possible [6]. The term to wean comes from an ancient phrase that means to accustom to [7]. Weaning is defined as, the systematic process of introduction of suitable food at the right time in addition to the mother's milk in order to provide needed nutrition to the baby [4]. Weaning is very important for infant to rapid build-up of the baby muscle as well as other tissue [7]. Complimentary food is a common cultural practice followed by Nepalese people, it also plays vital role in the child's milestone for growth and development [8] rapid growth of body during the first year of life and specifically the first 6 months postpartum requires an adequate supply a nutrient to cope with rapid build-up of body muscle and other tissue [2]. Weaning is often advantages in reducing early infant mortality death. Although timing of weaning varies across societies but is always determined by the mother characteristic, choice, knowledge and perceptions about child health or cultural beliefs related to feeding [8]. Feeding practice and reduction of artificial feeding could save an estimated 1.5 million children a year. The delayed introduction of semisolid foods in a major causes of child malnutrition in South Asia. According to Asia Hunger Facts; prevalence of under nutrition across different regions of Asia: undernourished-Caucasus and central Asia 7\% of population, Eastern Asia 14.6\% of population, China $9.3 \%$ of population, South Asia $15.7 \%$ of population, South East Asia 9.8\% of population, West Asia $3.4 \%$ of population.

The nutritional adequacy of complimentary food is essential for the prevention of infant morbidity and mortality including malnutrition and overweight [2]. Ten millions of children under the age of 5 years old die each year. More than half of the deaths occur because of malnutrition [9]. Malnutrition makes a child susceptible to infections and delays recovery thus increasing mortality and morbidity. Malnutrition is one of most widespread conditions affecting child health [2]. Everyday on an average more than 26000 children under the age of five die around the world.

Bhanderi \& Choudhary [1] Over 200 million children in developing countries under the age of five are malnourished. Malnutrition contributes to more than half of the nearly 12 million under-five year's deaths in developing countries each year [1]. Approximately 70\% of world's malnourished children live in Asia, resulting in the region having the highest concentration of childhood malnutrition. Bangladesh has the highest prevalence of child under weight of all countries in the world except North Korea, and only seven countries have a higher prevalence of child stunting than that of Bangladesh [10]. $41 \%$ of children under 2 years are under weight and $43 \%$ are stunted due to malnutrition. According to UNICEF; 2008-2012 severe underweight $10.4 \%$, 2008-2012 moderate \& severe stunting $41.3 \%$, 2008-2012 moderate \& severe wasting $15.6 \%$, 20082012 moderate \& severe over weight $1.5 \%$. According to Asia Hunger Facts; prevalence of stunting and wasting in Asia under 5 populations; Caucasus \& Central Asia stunting 17.3\%, wasting 4.1\%. Eastern Asia (China) stunting 8.5\%, wasting 2.3\%. South Asia stunting $37.5 \%$, wasting $25.3 \%$. South East Asia stunting $27.8 \%$, wasting 9.8\%. West Asia / Middle East stunting $17.9 \%$, wasting $3.4 \%$. Worldwide 6.9 million children below the age of five years died in 2011 and $33 \%$ of these deaths are linked to malnutrition.

A nutritional status child under 2 years is a sensitive indicator of development of any country. Inadequacy of the weaning foods contributes significantly to the high rates of micronutrient deficiencies and malnutrition, often observed in low income countries. The link between infant weaning practices and malnutrition is well known. National Nutrition survey 2011 revealed the high prevalence of malnutrition among children <5 in Pakistan [4]. Infant mortality rate total 53.9 deaths/1000 live birth. State of world and Pakistani children; Global 6.6 million under 5 years deaths/year, 0.35 million Pakistani under 5 years children die/year, 1-2 child every minute.

In India of an average mother, although poor in nutritional status, has a remarkable ability to breast feed her infant for prolonged periods, Sometimes, extending to nearly 2 years [4]. India ranks second in the world for child malnutrition $(43.1 \%)$ after Timor lest $(47.7 \%)$ according to world health statistics report (WHO, 2012). High malnutrition rates in the country pose a significant obstacle in achieving better child health outcomes. India still has the highest number of under- weight children under five in the world and 70 percent of children are anaemic. The proportion of undernourished people in the overall, population has fallen from $21.5 \%$ in $2004-2006$ to $17 \%$ in $2011-2013$ according to International Food Policy Research Institute (IRPRI) estimates [11].

Bangladesh regarding determinants of infant and young child feeding practices, it was reported that young infants under 6 months of age, $42.5 \%$ were exclusively breastfed and among those aged 6-9 months, $62.3 \%$ received complimentary foods in addition to breast milk [2] Bangladesh is a developing country having $2.1 \%$ growth rate with infant mortality and under 2 children mortality 56 and 77 respectively. Malnutrition is widely recognized as a major health 
problem in developing countries [7]. According to key statistics; newborn mortality rate (NMR) 24/1000 newborn, Infant mortality rate (IMR) 33/1000 infants, Under 5 mortality rate (U5MR) 41/1000 children (under5 years of age).

Knowledge of weaning foods and practice is an important aspect of child health and development. At the age of 1 year the child should receive and fruits [4]. Under 2 children suffer various nutritional problems in rural and slum areas [7]. In this regard, mother proper knowledge on weaning food and time may play vital role to enhance health status of children. Knowledge of mothers has an important role in the maintenance of nutritional status of the children. Adequate knowledge regarding various aspects of feeding practices during pregnancy and during infancy is very essential especially among females as they are going to influence the feeding practices of this vulnerable group [11]. We know the knowledge attitude and practice about infant feeding and weaning food are varies in our population depending on their location, taboos, education, traditional beliefs etc. With this view this study was carried out to see the knowledge attitude \& practice about infant feeding and weaning food among the mothers of under 2 years children.

\section{LITERATURE REVIEW}

This study had given a review of the literature relevant to this study. The discussion covers the relevant article and their finding or results:

One study found that Petlad town, a semiurban area of Anand district, Gujarat, a study was conducted to assess the feeding and weaning practice in under 2 years children. That community-based study was cross-sectional study involved out of total 300 children examined; systematic sampling method was used to select the sample. the study showed that feeding and weaning practice in under 5 years children are strongly influenced by factors like mothers' education, provision of antenatal care, place of delivery \& prevailing socio-cultural beliefs but not by socio economic status. In these study found that $229(76.3 \%)$ children were feed colostrum, $223(76.6 \%)$ children received exclusive breast feeding, top feeding was initiated in $70(23.3 \%)$ children, $230(76.7 \%)$ children were not given any top feeding, $242(80.7 \%)$ children were put on weaning food, 207 ( $76.9 \%$ ) mother know about colostrum, $121(44.9 \%)$ mother knew the ideal age of weaning (2).

Another study found that Jinnah Hospital, Lahore has conducted a study to assess the mother's knowledge and practices of complementary feeding. They included sample 250 mothers whose babies age 612 months, were selected by non-probability purposive sampling technique, use cross-sectional study design. The result showed mothers have adequate knowledge on area like early exclusive breast feeding, they have not much satisfactory knowledge in area like complementary feeding, hygiene practice etc. $79.6 \%$ mothers exclusive breast feed their babies and $84 \%$ continue breast feed along with complementary feeding , correct knowledge of initiation of complementary feeding was found in $54 \%$ of mothers but it was practiced by only $43 \%$, overall knowledge of $24 \%$ mothers was good and $28 \%$ had poor knowledge of complementary feeding whereas only $7 \%$ women had good overall practices, statistically significant association of education of the parents with the practices of complementary feeding ( $\mathrm{p}$-value $=0.012$ and 0.0295 of mothers and fathers). The study also showed that more than one third of mothers had poor overall knowledge regarding complementary feeding and very few mother had good overall practice.

Other study found in Dhamrai has conducted a study to determine the mother's practice of infant feeding. That study was cross-sectional descriptive study involved in 320 villagers of selected village among the mothers who had baby up to 1 year and above, simple random sampling technique was adopted to select the sample of population. The result showed that mother have adequate knowledge on area like breastfeeding, weaning food, exclusive breast feeding etc. The result also showed that $137(42.8 \%)$ breastfed their infants by the duration of 9-12 months and 124 $(38.8 \%) \& 59(18.4 \%)$ were 6-9 months and less than and equal to 6 months , $145(45.3 \%)$ were give breast feed 3-4 times in a day and $116(36.3 \%)$ more than 4 times a day ,160 (50\%) did not know the reasons for not given exclusive breast feeding , $90(28.1 \%)$ were ill and $15.6 \%$ due to insufficient breast milk, $91.6 \%$ were taking weaning food and $8.4 \%$ were not taking weaning food , $315(98.4 \%)$ were aware about the usefulness of breast feeding and 5(1.6\%) were not,269 (84.1\%) were aware about the knowledge on complementary food and $51(15.9 \%)$ were not.

Another study found in Nepal, Navi Mumbai. The study has conducted to assess the mother knowledge of regarding weaning process in infants. The study was cross-sectional study involved in 50 mothers of infants above 6 months of age, purposive sampling technique was used to select the sample. The result showed majorities of the mothers are having wrong concept about weaning and are not knowledge about current weaning recommendation. The study also showed that $42 \%$ mothers of infants had poor knowledge about the weaning process, $38 \%$ of the samples had average knowledge regarding weaning process, $20 \%$ of the mothers are well aware and had good knowledge regarding weaning process, $69.23 \%$ of sample responded correctly to the question no. about the age at which semi-solid food should be introduced, $15.38 \%$ of samples responded correctly to question about the age at which non - vegetarian items should be introduced (3). 
Another study found in Lahore, Pakistan. The study was conducted to develop and evaluate effectiveness of weaning education tool among mother's infants aged 6-12 months. Two staged study design was used to evaluate effectiveness of weaning education tool. Stage one consisted of need assessment and stage two was a quasi- experimental research design involved in 30 mothers. The result showed that $26 \%$ thought weaning should be started when infants is 4 months, majority mothers $(31 \%)$ thought cerelac was ideal weaning food.

Another study found in Moulana Bashani Medical College and Hospital (MBMCH) Uttara, Dhaka. They study have conducted a study to assess mother's knowledge about factor influencing the weaning. They included sample mothers who attend with them under 2 children during March 2005 to May 2006 in the outpatient department of paediatrics in Moulana Bashani Medical College and Hospital (MBMCH) Uttara Dhaka. The result showed that majority (59\%) knowledge about weaning and $37 \%$ poor weaning knowledge and $4 \%$ medium weaning knowledge.

Other study found in Jhangad Community of Ihorahat V.D.C, Nepal. They have conducted a study to assess the level of knowledge and practice regarding weaning of infants. They include sample 50 mothers, use descriptive method, convenient purposive sampling method was used to select the sample. The result showed that most of the mothers had heard about weaning practice, only $76 \%$ mothers know about ideal weaning time. $92 \%$ used foods for weaning from local sources like rice and pulses $(43 \%)$ because of its easy availability. $69.35 \%$ started weaning after 8 months, 20 (40\%) of mother replied that weaning helps in overall growth and development and only $4(8 \%)$ replied that it helps in avoiding malnutrition. Study finding also showed that $37(74 \%)$ have no health hazard during weaning but the remaining $13(26 \%)$ faced problems, $7(54 \%)$ had diarrhea.

Another study found in Northern Kordofan State, Sudan. They have conducted a study to assess mother's practice of infant feeding and weaning whose children zero- 24 months. The study was observational case finding community-based study involved in 250 families, simple random sampling technique was used to select the sample. The result showed that breast feeding was initiated immediately after birth within $83.6 \%$ of mothers. Almost half of the mothers (55.2\%) stopped breastfeeding when the child was 24 months old; the majority of the mothers $(91.6 \%)$ introduced complementary foods before six months of age while only $8.4 \%$ started given foods at six months and over.
Another study was found in Mohie Hissowal and Shehbazpura village of Ludhiana district of Punjab. They had conducted to assess the mother's knowledge. They include sample of 120 mothers of children with the age group of 1-3 years, data were collected using a pretested questionnaire. The result showed that maximum knowledge in the area of hygiene and sanitation $(93.8 \%)$ followed by feeding practices $(73.7 \%)$ and pregnancy (60\%), they have not much satisfactory knowledge in the area like anemia $9.8 \%$, $38.3 \%$ of mothers had correct knowledge that risk of anemia is more during pregnancy and only $8.3 \%$ of mothers knew that anemia during pregnancy results in low birth weight baby. Also showed that $91.7 \%$ understand that it is necessary to wash hands before eating, $85.8 \%$ of mothers had knowledge about the fact that the colostrum should be given to newborn babies, $84.2 \%$ of mothers were aware of the practice of giving mother milk as the first food, $85.8 \%$ of mothers had correct knowledge about weaning foods.

\section{The rationale of the Study}

In Bangladesh, most people lived in the area and illiterate. Maximum mothers are not aware of infant feeding and weaning. Their knowledge level is poor. Mothers are the primary caregivers of the child. So, they need to be sufficiently aware regarding infant feeding and weaning food. The purpose of the study is to assess the knowledge, attitude, and practice about infant feeding and weaning food among mothers of children. Because mothers play a major role in promoting the health of children. This study will provide valuable information about infant feeding and weaning will create awareness among the mothers based upon the result of this study.

Mother is the most central person in a child's life for both physical and psychological development. From the very first moments of life, a baby interacting with their mother. Mothers' health, education, views \& approaches regarding child-rearing practices are important indicators on the path of a child's health. Less knowledge among mothers brings a negative attitude and fear which leads to affect the nutritional status of their children. Knowledge is necessary to take any good decision. Mother's knowledge will help to change the nutritional situation of children that will improve the rate of child malnutrition. Promoting the mother's knowledge about infant feeding and weaning helps either directly or indirectly improving nutritional status. So, we decided to conduct a study about the knowledge of mothers about infant feeding and weaning food to prevent child illness that contributes to child mortality in the country.

\section{Research question}

What is mothers' knowledge, attitude, and practice regarding their infant feeding and weaning food? 


\section{THE OBJECTIVE OF THE STUDY General Objective}

- To assess the overall knowledge attitude and practice about infants feeding and weaning among the mothers of under 2 years children at M.A.G Osmani Medical College Hospital.

\section{Specific Objective}

- To assess the knowledge about infant feeding and weaning among the mothers of under 2 years children.

- To find out the attitude about infant feeding and weaning among the respondent.

- To identify the infant feeding and weaning practice among the mothers.

- To determine the socio-demographic characteristic of the respondent.

\section{METHODOLOGY}

This study was conducted to assess the level of knowledge attitude and practice about infant feeding and weaning food among the mothers of under 2 years children. The study was carried out with the following methodology consists of study design, setting, population, period, sample, \& sample size, sampling technique, instrument, selection criteria, the validity of the questionnaire, reliability of the questionnaire, data collection procedures, ethical considerations, and data analysis.

\section{Study Design}

A hospital-based descriptive type of crosssectional study to assess the knowledge, attitude \& practice about feeding and weaning food among mothers of under 2 years children.

\section{Study Setting}

This study was conducted at the pediatric ward in M.A.G. Osmani Medical College Hospital Sylhet, Bangladesh. The pediatric ward of SOMCH is situated on the $4^{\text {th }}$ floor of this hospital.

\section{Study Population}

The study population consisted of mothers whose children were admitted to the paediatric ward in M.A.G. Osmani Medical College Hospital, Sylhet.

\section{Study Period}

The study period was from $1^{\text {st }}$ October 2016 to $31^{\text {st }}$ December 2016.

\section{Study Sample}

The sample of this study was mothers of under 2 years whose children were admitted to the paediatric ward in M.A.G. Osmani Medical College Hospital.

\section{Sample Size}

The total number of respondents 100 were selected as the sample size for this study.

\section{Sampling Technique}

A non-probability convenience sampling technique was used in this study. Mothers whose infants were admitted to M.A.G. Osmani Medical College Hospital were participating in this study. This study was assured that confidentiality and privacy would be maintained.

\section{Inclusion Criteria}

- Mothers of an infant in M.A.G. Osmani Medical College Hospital.

- Mothers of infants who gave informed consent.

- Mothers who are willing to participate in the study.

\section{Exclusion Criteria}

- Mothers of children who are not willing to participate in the study

- Mothers whose children physically and mentally ill

\section{Research Instrumentation}

The instrument used for the study was the semi-structured questionnaire developed by the researcher. Questionnaires consist of the parts:

Part-1: This part consists of 8 items from collected socio-economic and demographic data including the mother's age, religion, live in, education, marital status, occupation, family income, and babies' age.

Part-2: This part was used to collect data knowledge related information of the mothers about infant feeding and weaning. The Questionnaire consist of 15 items including-exclusive breastfeeding, benefits, contraceptive benefits, nutrition, encourages bonding, hygiene, weaning, protection, bottle feed.

Part-2: This part was used to collect data attitude related information of mothers about infant feeding and weaning. This part consists of 9 items including-colostrum, breastfeeding, urination, first food introduced, early weaning.

\section{The validity of the questionnaire}

The content of this questionnaire was validated for appropriateness and accuracy by one expert in this field. The expert consists of a lecture from the department of community medicine. The researcher further modified the questionnaire based on expert comments and suggestions.

\section{Data Collection Procedure}

Data were collected from the pediatric ward in M.A.G Osmani Medical College Hospital, Sylhet Bangladesh from $1^{\text {st }}$ January to $30^{\text {th }}$ January 2017. Our data collection procedure is divided into two phases: preparation and implementation. 


\section{Preparation Phase}

The proposal was approved by a letter requesting permission to collect data by the principal of Sylhet Nursing College, Sylhet. Then the researcher met and submitted. The letter requesting permission to collect data to the Director of Sylhet Osmani Medical College, Hospital in Bangladesh. The researcher explained the objectives, study method, and benefit of the study to the Director. The researcher had met with the head nurse of the podiatric ward and explained the objectives, study methods, and benefits of the study. She also requested help to identify the subjects who met the inclusion criteria.

\section{Implementation Phase}

The researcher introduced himself to the eligible subjects and explained the objectives, their rights, and benefits of the study, and invited them to participate in the study. The subject who is agreed to participate in this study were asked to nonverbal consent (interview). They were informed about how to complete the questionnaires. The questionnaires were checked to make sure they were complete.

\section{Data processing and Data Analysis}

After the collection of data, the responses of each participant were organized. Data was entered into the computer into a database in the software packagestatistical package for the Social Science (SPSS 17.0) using descriptive statistics such as frequency distribution, percentage, categories. All scores and percentages were computed and presented in tabular form, charts, and graphs as appropriate.

\section{RESULTS}

This descriptive type of cross-sectional study was conducted to see the knowledge, attitude, and practice about infant feeding and weaning food among the mothers of under 2 years children in Sylhet M.A.G Osmani Medical College Hospital, Sylhet. Total respondents were 100 . The purpose of analyzing was to use the data to describe many variables. Data were collected, edited, and analyzed according to the nature of the variables. The results were provided as percentages and pie charts and bar charts and tables. This study showed that 100 infant mother's knowledge, attitude, and practice about infant feeding and weaning food from October 2016 to December 2016.

Distribution of the respondents by age

\begin{tabular}{|c|c|c|}
\hline Age(Years) & Frequency & Percentage \\
\hline $15-24$ & 46 & $46.00 \%$ \\
\hline $25-34$ & 48 & $48.00 \%$ \\
\hline $35-44$ & 6 & $6.00 \%$ \\
\hline Total & 100 & $100 \%$ \\
\hline
\end{tabular}

The table showed that $(n-46) 46 \%$ of the respondents were 15-24 years of age and (n-48) $48 \%$ of respondents were 25-34 years of age and (n-6)6\% of the respondents were 35-46 years of age.

Distribution of the respondents by educational qualification

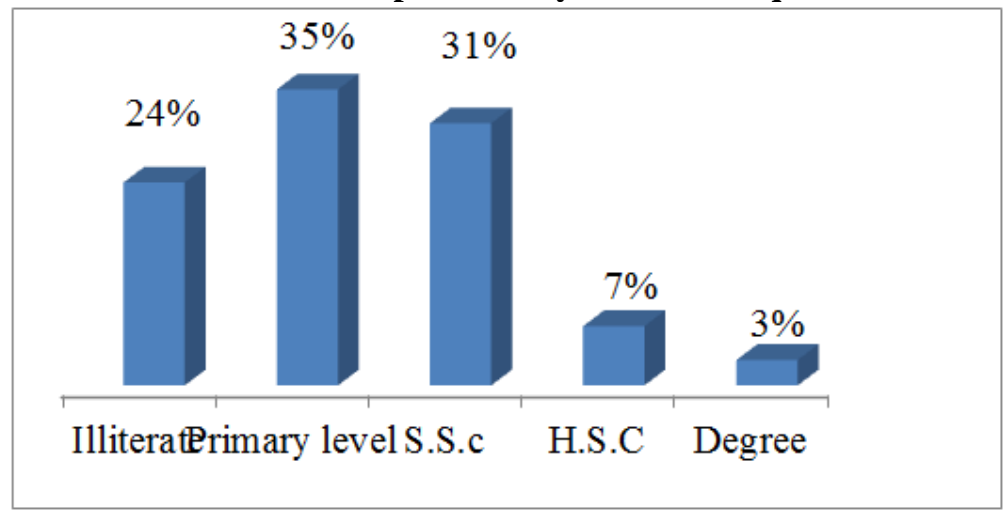

The figure showed the educational qualification of the respondents. (n-35) $35 \%$ of the respondents were primary level, (n-31) $31 \%$ of the respondents were S.S.C, (n-24) $24 \%$ of the respondents were illiterate, $(n-7) 7 \%$ of the respondents were H.S.C $\&(n-3) 3 \%$ of the respondents were degree. 


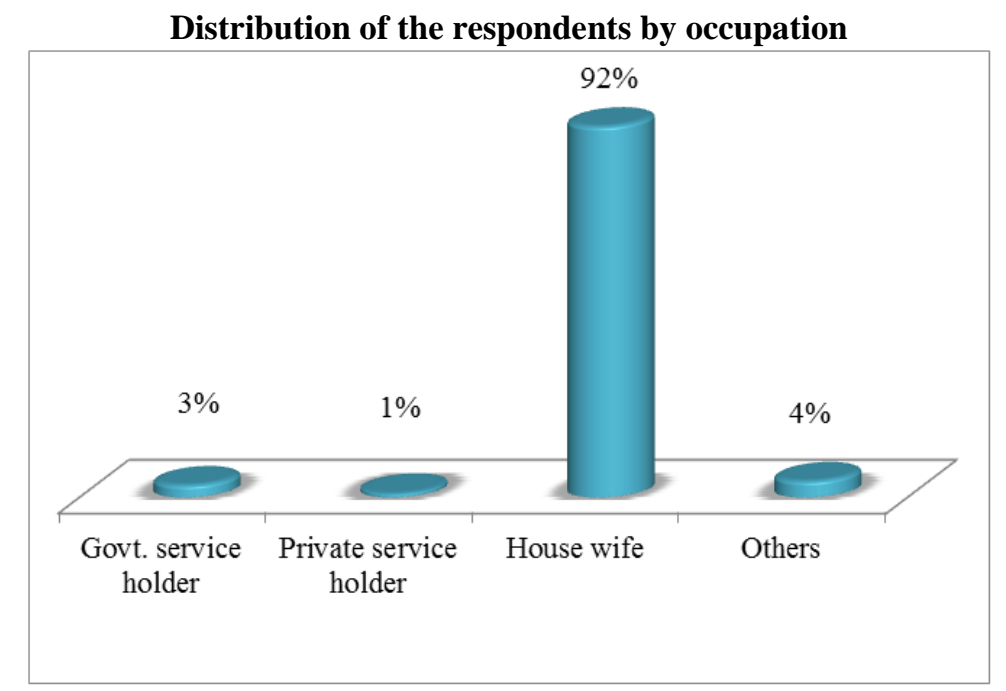

The figure showed the occupation of the respondents. It revealed most of the respondents (n-92) $92 \%$ were housewives, (n-3) $3 \%$ of the respondents were govt. service holder, (n-1) $1 \%$ were private service holder, (n-4) $4 \%$ of the respondents were other occupation.

Distribution of the respondents by monthly family income

\begin{tabular}{|c|c|c|}
\hline Monthly family income (taka) & Frequency & Percentage \\
\hline $5000-10000$ & 46 & $46.0 \%$ \\
\hline $10001-15000$ & 17 & $17.0 \%$ \\
\hline $15001-20000$ & 19 & $19.0 \%$ \\
\hline $20001-25000$ & 4 & $4.0 \%$ \\
\hline $25001-30000$ & 9 & $9.0 \%$ \\
\hline $30001-35000$ & 2 & $2.0 \%$ \\
\hline $35001-40000$ & 3 & $3.0 \%$ \\
\hline Total & 100 & $100.00 \%$ \\
\hline
\end{tabular}

The table showed the monthly family income of respondents. Among the total 100 respondents more than two-fifth (n-46) 46\% have a family income of
5000-1000 and only (n-3) 3\% have 35001-40000 taka per month.

Distribution of the respondent's knowledge by the duration of exclusive breastfeeding

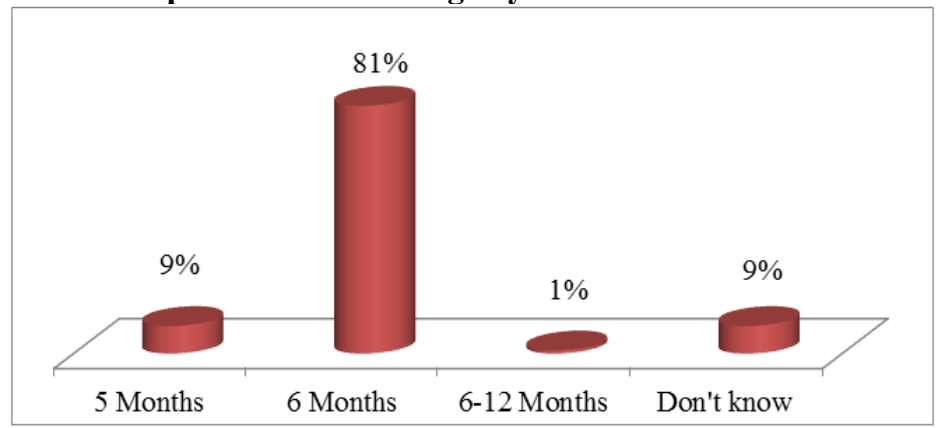

The table shows the knowledge of the mother about the duration of exclusive breastfeeding. Majority (n-81) $81 \%$ of the respondents answered 6 months, (n9) $9 \%$ of the respondents answered 5 months, (n-1) $1 \%$ respondents answered 6-12 months and (n-9) 9\% respondents answer didn't know.

$\begin{gathered}\text { Distribution of the respondent's knowledge by } \\
\text { benefits of breast milk }\end{gathered}$
\begin{tabular}{|c|c|c|}
\hline Category & Frequency & Percentage \\
\hline Yes & 25 & $25.00 \%$ \\
\hline No & 75 & $75.00 \%$ \\
\hline Total & 100 & $100.00 \%$ \\
\hline
\end{tabular}


The result shows the knowledge of mothers about the benefits of breast milk. Three fourth (n-75) $75 \%$ of the respondents did not know about the benefits of breast milk and (n-25) $25 \%$ of respondents were known about it.

Distribution of the respondents by nutritious of
breastfeeding
\begin{tabular}{|c|c|c|}
\hline Category & Frequency & Percentage \\
\hline Yes & 94 & $94.00 \%$ \\
\hline No & 6 & $6.0 \%$ \\
\hline Total & 100 & $100.00 \%$ \\
\hline
\end{tabular}

The table shows the respondents' knowledge about the nutritious of breastfeeding. Among the total 100 respondents, (n-94) $94 \%$ give a positive answers and only (n-6) $6 \%$ give a negative answers.

\section{Part-1}

\section{Socio-economic and Demographic Information of Infant's Mothers}

Present the study participants' age. They were divided into 3 groups from 15-44 years. Almost mothers who were involved in this study were age group $46 \%$ were in the use of 15-24 years (Table-1), study was age group $48 \%$ were in the use of $25-34$ years (Table-1), study was age group $6 \%$ were in the use of $35-44$ years (Table-1). There were $83 \%$ of respondent's faith in Islam and $17 \%$ of respondents were faith in Sanaton (Figure-1). This study found $60 \%$ of respondents were lived in rural areas and $40 \%$ of respondents were lived in the urban area (Figure-2). Educational qualification of mothers found $35 \%$ were primary level, $31 \%$ were S.S.C level, $24 \%$ were illiterate, $7 \%$ were HSC level and only $3 \%$ were Degree (Figure-3). This study found that the majority of the respondents $96 \%$ were married (Figure-4). By occupation, more than $92 \%$ of the respondents were housewives, Govt. service holder $3 \%$, and private service holder only $1 \%$ (Figure-5). In this study population, most of the family monthly income was (5000-10000) 46\%. There were divided into 4 group babies age from ( 1 months-24 month) and most $62 \%$ of babies age were (7-12) months (Table-3).

\section{Part-2}

Knowledge related information's of mothers

$81 \%$ of mother's known duration of exclusive breastfeeding was 6 months, 9\% known duration of exclusive breastfeeding was 5 months, $1 \%$ known duration of exclusive breastfeeding was 6-12 months and $9 \%$ don't know the duration of exclusive breastfeeding. This study showed that a mother's good knowledge about the duration of exclusive breastfeeding. Among the mothers interviewed, $75 \%$ of mothers did not know about the benefits of breast milk, and only $25 \%$ of mothers known about the benefits of breast milk. This study showed that the mother had poor knowledge about the benefits of breast milk (Table-4). Among the mothers, $55 \%$ of mothers believed breastfeeding has not contraceptive benefits, and $45 \%$ of mothers believed breastfeeding has not contraceptive benefits. This study showed that mother knowledge was poor about breastfeeding has contraceptive benefits (Table-5).

\section{DISCUSSION}

The study was carried out to assess the postnatal mothers. Knowledge and attitude about newborn care in Sylhet Osmani Medical College Hospital. It was a descriptive type of cross-sectional study, conducted among 100 mothers the significant findings study in the areas of postnatal mothers. Knowledge and attitude about newborn care were discussed according to analysis. In this study, results showed that the major findings of the sociodemographic variables indicate that $48 \%$ of mothers were between 25-34 years and the minimum $6 \%$ were in the age group of above 35-44 years.

G.V. Kulkarni, M.M. Angadi, V.M. Sorganvi, India 2015 conducted among 245 mothers. The childbearing women belong to the age group of 22-24 years $(44 \%)$, followed by the age group of $25-29$ years $(31 \%)$ and $15-19$ years $(13 \%)$ respectively.

Shazia Samad Mohsin, Abdul Sattar Shaikh, Rehana Shaikh, Nighat Haider, and Art Parkash, Karachi 2014 conducted among 138 mothers. The commonest age group was $20-30$ years in which $71 \%$ of respondents were found. This study showed that the educational qualification of respondents $35 \%$ were primary level, $31 \%$ were S.S.C level, $24 \%$ were illiterate, $7 \%$ were H.S.C and $3 \%$ respondents were Degree.

Dr. Mohoshina Karim, Dr. Shayela Farah, Dr. Jannatul Ferdousi, Dhaka 2012 conducted among 320 mothers. The primary educational level of respondents was $151(47.2 \%)$ Secondary educational level was 96 $(30 \%)$ and illiterate mothers were $71(22.2 \%)$. Ayesha Saeed, Shafia Shahid, Fatima Hassan, Mahnaz Nasir Khan, Amina Muhammad Saeed, Pakistan 2015 conducted among 30 mothers. The majority of the mothers $42 \%$ were illiterate.

This study showed that more than two-fifth (46\%) have a monthly income of 5000-10,000 and only $3 \%$ have 35,001-40,000 TK/months. Kiranpreet Kaur, Kiran Grover, and Navjot Kaur, Ludhiana 2015 conducted among 120 mothers. The family income of the majority $(74.2 \%)$ of the subjects range between Rs.5000-20000 per month and 8.3\% were having less than Rs. 5000 per month.

This study expressed that the major findings of the knowledge-related information indicate that more than four-fifth $(81 \%)$ respondents were answered about 6 months. Nearly one-fifth $(9 \%)$ respondents were answered about 5 months. These findings are similar to 
Wonder Garoma Berra, Ethiopia 2013 conducted the study among 240 mothers. The majority $(80 \%)$ of the respondent's responded duration of exclusive breastfeeding up to 6 months, $9.6 \%$ respondent's responded exclusive breastfeeding 6-12 months, $2.9 \%$ respondent's responded exclusive breastfeeding their babies at least the first 12-23 months.

This study showed that one-fourth $(25 \%)$ of the respondents were known about the benefits of breast milk, on the other hand, most of the respondents threefourth $(75 \%)$ did not know about the benefits of breast milk. These findings are similar to Eman $\mathrm{S}$. Mohammed, Eman R. Ghazauey, and Eptesam E. Hassan, 2014 conducted a study among 307 rural mothers. The majority $(97.9 \%)$ of the mothers had good knowledge about the advantages of breastfeeding for the child.

This study showed that the majority (94\%) of the respondents give a positive answer about the nutrition of breastfeeding and $6 \%$ of the respondents give a negative answer.

Wondo Garoma Berra, Ethiopia, 2013 conducted among 240 mothers. $95.4 \%$ of mothers know that breast milk is nutritious.

This study showed that the majority (91\%) of the respondents were answered started time of weaning food after 6 months. Another study by Kiranpreet Kaur, Kiran Grover, and Novjot, Ludhiana 2015 conducted among 120 mothers. The majority $(85.8 \%)$ of the respondents responded weaning should be started after 6 months. Dipty Subba, S. Bhattarai, and R. Roy, Nepal 2014 conducted among 50 mothers. $75 \%$ of mothers said that started time of weaning after completion of 6 months of age.

This study showed that more than four-fifth $(85 \%)$ of respondents don't know breastfeeding protects the child from illness. Another study by Kiranpreet Kaur, Kiran Grover, and Novjot, Ludhiana 2015 conducted among 120 mothers. $70.8 \%$ of mothers known for breastfeeding protects the child from illness.25.8\% of mothers don't know about breastfeeding protect the child from illness.

This study showed that more than $68 \%$ of respondents answered that hotchpotches are given as a first weaning food and only $16 \%$ answered that cerelac was given as a first weaning food. Another study of Ayesha Saeed, Shafya Shahid, Fatima Hassan, Mahnaz Nasir Khan, and Amina Muhammad Saeed, Lahore Pakistan 2015 Conducted among 26\% of mothers' rusk given as a first weaning food.31\% of mothers cerelac given as a first weaning food.
This study showed that $50 \%$ of the respondents were a known frequency of complementary feeding 2-3 meals per day. More than $28 \%$ of respondents give answered 5-6 meals per day and 7\% of respondents don't know about the frequency of complementary feeding. These findings are similar to Seema Hasnanain, Muhammed Ashraf Majrooh, and Raana Anjum, Lahore Pakistan 2013 conducted among 250 mothers. 205(82\%) mothers knew the correct frequency of food per day to be given. Only 106 (42\%) were given the correct frequency to their infants 2-3 meals per day.

This study showed that most of the respondents more than $78 \%$ of respondents answered that feeding babies with bottles are safe. More than $22 \%$ of respondents were aware that feeding babies with bottles are not safe. Another study by Kiranpreet Kaur, Kiran Grover, and Novjot, Ludhiana 2015 conducted among 120 mothers. Around $69.2 \%$ of mothers were aware that feeding babies with bottles are not safe.

This study showed that four-fifth $(80 \%)$ of the respondents feed colostrum. Nearly fifth $(17 \%)$ threw the colostrum. Eman. Mahammed, Eman R. Ghazawy, and Eptesam E. Hassan 2014 conducted among 307 mothers. Thirty Quarters (74.2\%) of mothers fed colostrum.

This study showed that most of the respondents more than two-fifth were known about breastfeeding the baby as soon as possible soon after delivery. Nearly one-fifth of respondents $(14 \%)$ were answered within half an hour. More than one-fifth $(27 \%)$ within 1 hour and nearly one-fifth (14\%) don't know about breastfeeding soon after delivery. Francis, Mireille, David, Pascal, Carles and Christopher practice in the study (44.3\%) as higher than that found nationwide $22 \%$ for breastfeeding within one hour and $20 \%$ for exclusive breastfeeding.

This result showed that $28 \%$ of mothers answered the time of breastfeeding 10-12 times and 28\% 8-10 times and 98\% 5-6 times per day. Dr. Mohoshina Karim, Dr. Shayela Farah, Dr. Jannatul Ferdousi, Dhaka 2012 conducted among 320 mothers. Among them, 145(45.3\%) were given breastfed 3-4 times in a day and $116(36.3 \%)$ more than 4 times a day.

This study showed that three-fourth $(75 \%)$ of respondents answered that they were aware of the continuation of breastfeeding above 2 years \& $(6 \%)$ respondents don't know. Kiranpreet Kaur, Kiran Grover, and Navjot Kaur Ludhiana,2015 conducted among 120 mothers. Most of the mothers(46.7\%) answered 2 years, $(11.7 \%)$ of the respondents answered 1 year 6 months, $(2.5 \%)$ of the respondents answered 1 year, $28.3 \%$ of the respondents answered 2 years 6 months, and $10.8 \%$ of the respondents answered 3 years continuation of breastfeeding. 
This study showed that most of the mothers (83\%) were answered breast milk as a first introduced food, $15 \%$ were answered, honey. Kiranpreet Kaur, Kiran Grover, and Navjot Kaur Ludhiana,2015 conducted among 120 mothers. The majority (84.2\%) of mothers were aware of the practice of giving mothers milk as the first food about $15 \%$ of mothers were given ghutti as the first food. Tahani Babiker Elyas, Sudan 2015 conducted among 780 mothers. $26 \%$ of mothers breastfeed the child soon after birth, $13 \%$ introduced boiled water, $23 \%$ give sugar soon after delivery. In this study half $(50 \%)$ were answered reasons for early weaning due to insufficient milk, $16 \%$ were answered child illness, $16 \%$ were answered mothers' illness and only $12 \%$ were answered early growth. Dr. Mohoshina Karim, Dr. Shayela Farah, Dr.Jannatul Ferdousi, Dhaka 2012 conducted among 320 mothers. Reasons for early weaning due to $90(28 \%$ ) were ill and $15.6 \%$ due to insufficient breast milk. Tahani Babiker Elyas, Sudan 2016 conducted among 780 mothers. $42 \%$ of mothers weaned their children due to insufficient milk, $14.3 \%$ due to mothers' illness.

This study showed that food is given after 6 months up to 2 years $43 \%$ give fish-meat-egg-milk, $33 \%$ give vegetables, $18 \%$ give table food. Kiranpreet Kaur, Kiran Grover, and Navjot Kaur Ludhiana,2015 conducted among 120 mothers. $27.5 \%$ of the mothers give meat and egg should be added to the child diet and $93.3 \%$ give nutritious snacks.

In this study the result showed that $69 \%$ of mothers had an average level of knowledge, $23 \%$ of mothers had a good level of knowledge and only $8 \%$ of mothers had poor knowledge. These findings are similar to Seema Hasnanain, Muhammed Ashraf Majrooh, and Raana Anjum, Lahore Pakistan 2013 conducted among 250 mothers. The overall knowledge of 61(24\%) mothers is good knowledge and 120(48\%) had satisfactory knowledge. In this study, the result showed that $54 \%$ of mothers had a positive attitude and $46 \%$ of mothers had a very positive attitude. These findings are similar to Seema Hasnanain.

Muhammed Ashraf Majrooh, and Raana Anjum, Lahore Pakistan 2013 conducted among 250 mothers. The overall practice of $17(7 \%)$ mothers out of $250(>70 \%)$ was good but was poor in $122(49 \%)$ of mothers.

\section{RECOMMENDATION}

In the present study findings, it was evident that knowledge, attitude and practice about infant feeding and weaning food among the mothers of 2 years children were not satisfactory based on study findings the followings may be recommended-The health educational program may be conducted among the infant mothers to increase awareness on infant feeding and weaning at Pediatric Department of M.A.G Osmani Medical College Hospital, Sylhet.
Our country's media can play an important role in increasing awareness about infant feeding and weaning such as- exclusive breastfeeding, benefits of breast milk, weaning food started time, maintain personal hygiene before preparing baby food, duration of breastfeeding.

The hospital authority can be placed a wall television at the site of the breast-feeding corner outdoor in $\mathrm{SOMCH}$, for displaying, such as- exclusive breastfeeding, benefits of feeding, weaning food started time, maintain personal hygiene before preparing baby food, duration of breastfeeding. Further study also conducts to have a greater view regarding the knowledge, attitude, and practice about infant feeding and weaning food among mothers of 2 years children with a large sample population covering the whole of Bangladesh.

\section{CONCLUSION}

The cross-sectional descriptive study has focused on determine and assesses the mother's knowledge, attitude, and practice regarding infant feeding and weaning in M.A.G Osmani Medical College Hospital, Sylhet. This study was conducted at Sylhet M.A.G Osmani Medical College Hospital, Sylhet. The result of this study was providing important information that helps to developed mothers' knowledge, attitude, and practice about infant feeding and weaning food.

The data was collected from 100 respondents of Sylhet M.A.G Osmani Medical College Hospital, Sylhet. The study identified the mother's knowledge, attitude, and practice regarding infant feeding and weaning. So that increase mothers' knowledge, attitude, and practice about infant feeding and weaning required education program for the community. The study was provided valuable information, based on the finding it is cleared that the knowledge of mothers regarding infant feeding and weaning is poor and positive attitude inadequate. So, there are necessities to arrange health education sessions for mothers of under 2 years children with the main emphasis on the importance of infant feeding and weaning.

\section{REFERENCES}

1. Bhanderi, D., \& Choudhary, S. (2011). A community-based study of feeding and weaning practice in under 5 children in semi urban community of Gujarat. National Journal of Community Medicine, 2(2): 277-283.

2. Hasnain, S., Majrooh, M.A., \& Anjum, R. (2013). Knowledge and practice of mothers for complementary feeding in babies visiting pediatrics outpatient department of Jinnah Hospital, Lahore. Biomedica. 29: 221-230.

3. Karim, D. M., Farah, D. S., \& Ferdousi, D. J. (2012). Study on feeding practice of infants among 
the mothers in selected villages, at Dhamrai. $J$. Dhaka National Med. Coll. Hos, 18(02): 30-36.

4. Saeed, A., Shahid, S., Hassan, F., Khan, M. N. \& Saeed, A. M. (2015). Development and Evaluation of weaning Education tool among mothers' infants aged 6-24 months in urban slam of Lahore, Pakistan. International Journal of Scientific and Engineering Research, 6(8): 351-356.

5. World Health Organization, \& International Society of Hypertension Writing Group. (2003). 2003 World Health Organization (WHO)/International Society of Hypertension (ISH) statement on management of hypertension. Journal of hypertension,21(11), 1983-1992.

6. Kambli, S. (2012). Mothers knowledge regarding weaning process in infant. International Journal of Science and Research, 3(7): 1192-1197.

7. Khan, M. A. S., Hossain, M.M., Banik, A.K. (2007). Factors influencing the weaning knowledge of mothers of under 5 children: A hospital-based study. The Orion Medical Journal, 28: 287-289.

8. Subba, D., Bhattarai, S., \& Roy, R. (2014). Knowledge among mothers regarding weaning practice of Jhangad community of Jhorahat V.D.C, Nepal, 12(1); 54-59.

9. Mohammed, D.S.G.S. (2014). Infants feeding and weaning among mothers in Northern Kordofan State, Sudan. European Scientific Journal, 10(24), 165-181.

10. Hoque, M., Hossain, M.W., Parvin, M.N., Rahman, M.A. \& Hoque, M.M. (2014). Knowledge among mothers on under 5 children malnutrition: A cross sectional slum-based study. The American Journal of Innovative Research and Applied Sciences.

11. Kaur, K., Grover, K., Kaur, N. (2015). Assessment of nutrition knowledge of rural mothers and its effectiveness in improving nutritional status of their children. Indian Res, J. Ext. Edu, 15(4), 90-98. 